\title{
Stabilization of high-plasticity silt using waste brick powder
}

\author{
Rizgar A. Blayi ${ }^{1}$ - Aryan Far H. Sherwani ${ }^{1} \cdot$ Hawkar Hashim Ibrahim ${ }^{2}$ · Shwan Jalal Abdullah ${ }^{1}$
}

Received: 22 March 2020 / Accepted: 31 October 2020 / Published online: 12 November 2020

(c) Springer Nature Switzerland AG 2020

\begin{abstract}
The waste generated by brick industries in many countries around the world is increasing significantly with the continuous expansion of urbanization and industrialization, and as a result, more environmental and financial problems are brought about. The waste material out of bricks production could be used as a stabilizing material for high-plasticity silt $(\mathrm{MH})$ that has caused damage to different roads and buildings. This study aimed to investigate the effect of waste brick powder (WBP) on stabilizing high-plasticity silt and reduce the influence of WBP on the environment. An experimental study was performed to evaluate the effects of WBP on the geotechnical properties of MH soil. Atterberg limits, compaction characteristics, specific gravity, free swelling, unconfined compressive strength (UCS), California bearing ratio (CBR), and permeability were performed for natural and stabilized soil at different ratios $(6 \%, 12 \%, 18 \%, 24 \%$, and $30 \%$ by dry weight of the soil sample) of WBP. The test results showed that liquid limit, plastic limit, plasticity index, linear shrinkage, free swelling, and the coefficient of permeability are decreased by adding WBP, whereas specific gravity, maximum dry density, UCS, and CBR are increased by adding WBP.
\end{abstract}

Keywords Soil stabilization $\cdot$ Waste brick powder $\cdot$ High-plasticity silt $\cdot$ CBR $\cdot$ Subbase

\section{Introduction}

Plastic soil swells when it is water-saturated, while it shrinks when water is squeezed out of it [1]. Civil engineers face great challenges when designing structures on soils with high plasticity as their bearing capacity is so good when they are unsaturated yet and very poor when they are saturated [2]. Structures built on high-plasticity soils are subject to large uplifting forces caused by soil swelling. Massive amounts of soils are transported to engineering projects, such as roads, railways, and retaining walls which renders the whole process to be more laborious and costly [3]. Therefore, it is crucial to improve high-plasticity soil performance at sites where stable and safe engineering projects are ought to be built [4]. The methods used for stabilizing the soil's geotechnical properties are known as soil stabilization, which is a method for developing the physical and chemical properties of natural soil to achieve an engineering purpose.

One of the main building materials that have been used for construction in different countries is brick [5]. It has been used for building houses, sewages, and industries [6]. This produces a massive amount of waste brick which would have a detrimental impact on the environment [7]. It is crucial to use by-products or waste materials as natural stabilizing materials for foundations and highway embankments [3]. Waste brick powder (WBP) is one of the waste materials that could be used for soil stabilization, and a million tons of waste brick might be gathered annually [8]. In addition to the natural and economic advantages, brick waste for certain geotechnical works has unique features. $[1,2,9]$. For the construction of highways, the qualities of brick waste such as endurance, resilience, and excellent stiffness are necessary, and this could perform an important role in the effectiveness of subgrades and in reducing

Rizgar A. Blayi, rizgar.omar@soran.edu.iq | 'Department of Civil Engineering, Faculty of Engineering, Soran University, Soran, Kurdistan Region, Iraq. ${ }^{2}$ Civil Engineering Department, Salahaddin University-Erbil, Erbil, Kurdistan Region 44002, Iraq. 
the built pavement thickness. In this study, different ratios $(6 \%, 12 \%, 18 \%, 24 \%$, and $30 \%$ by dry weight of the sample) of WBP with $96 \%$ of the particles are less than $0.075 \mathrm{~mm}$, were used to improve the collected high-plasticity silt $(\mathrm{MH})$ from Soran City in the Kurdistan Region of Iraq.

\section{Literature review}

In the past decades, different attempts have been made for utilizing waste materials as a stabilizer by improving the geotechnical properties of weak soils, which consequently has reduced the potential impact of waste materials on the environment [10-15]. Among them is waste brick, as it has been utilized in different engineering projects [9]. For instance, WBP could be used in pavement design and as an alternative to the filler used in the asphalt mixture design $[16,17]$. In addition, crushed waste bricks were reported to have been used as subbase materials in pavements [18-20]. Furthermore, Poon, Chan [21] investigated the possibility of using waste concrete aggregate and crushed waste brick instead of subbase material. Moreover, waste bricks have been used by different researchers for soil stabilization as stabilizer material alone or mixed with other materials.

Saand et al. [7] investigated the use of brick kiln waste (BKW) for stabilization clay soil with various percentages $(5 \%, 10 \%, 20 \%, 25 \%, 30 \%, 35 \%$, and $40 \%$ of BKW). Based on the test results, with the addition of BKW, the clay soil was improved and becomes an acceptable material for using as subgrade material. Furthermore, Gupta et al. [22] studied the effect of using brick kiln dust (BKD) for improving six different subgrade soil materials with various plasticity. Various percentages (10\%, 20\%,30\%, and $40 \%$ ) of BKD were used for the stabilizing of soils, and results revealed that the use of BKD considerably increased the CBR as a main soil strength parameter. Consequently, the pavement thickness layers were reduced. Moreover, Gupta et al. [23] used BKD and pond ash wastes for the stabilization of clay soil to be used as a subgrade layer in the construction of flexible pavements. This research assesses the efficiency of BKD and pond ash in the improvement of the stiffness of clay soil under repetitive loading. The optimal percentage, according to the observations, of wastes for increasing CBR values when used alone was $30 \%$, whereas for the combination was $20 \%$.

Different laboratory tests were done by [3] to investigate the influence of using brick dust (BD), which is produced from cutting bricks, with a combination of fuel ash. Besides, fuel ash, Portland cement, and lime were used as a control; at the same time, the stabilizer materials were replaced by another by-product waste material that was ground granulated blast furnace slag. According to their study, different trials have been attempted to find the best proportion of waste materials to be used in construction without using soil material. Additionally, Hairulla Betaubun [2] studied the effect of utilizing waste brick on soft soil for unconfined compression strength (UCS) property only with different curing time. According to the unified soil classification system (USCS), the type of soil that was used in their research was low-plasticity clay $(\mathrm{CL})$. The main problems of $\mathrm{CL}$ soils are swelling, consolidation, and shrinkage while imbibing water, but none of them was mentioned. The bearing capacity of $C L$ soil is highly affected by its condition in terms of saturation, as it is good when it is unsaturated yet bad when it is saturated. Furthermore, Srikanth Reddy et al. [1] investigated the influence of using lime and brick powder for the stabilization of black cotton soil to be used as a subbase material. The mixtures prepared from brick powder (BP) and limestabilized black cotton soil (LSBCS) were of the following ratios, $20 \%$ BP + 80\% LSBCS, 40\% BP + 60\% LSBCS, 60\% $\mathrm{BP}+40 \% \mathrm{LSBCS}$, and $80 \% \mathrm{BP}+20 \% \mathrm{LSBCS}$. According to the results, the mixture of $20 \% \mathrm{BP}+80 \%$ LSBCS achieved maximum soaked CBR value. Moreover, Hidalgo et al. [5] conducted a series of UCS tests on two types of soils that were stabilized with $\mathrm{BD}$ and alkaline activators which were sodium hydroxide $(\mathrm{NaOH})$ and hydrated lime residue (HLR). The UCS samples were prepared with different ratios $(7 \%, 14 \%$, and $21 \%)$ of $B D$ and constant ratios of $1: 5$ and 6:4 for $\mathrm{NaOH}$ and $\mathrm{HLR}$, respectively. Besides, the samples were tested at various curing temperatures $\left(20-30^{\circ} \mathrm{C}\right.$, and $40-50{ }^{\circ} \mathrm{C}$ ), durations ( 7 and 28 days), and humidities (59\% and $95 \%)$. According to the results, stabilizing the soils by $\mathrm{BD}$ and alkaline activators has increased the soil strength by 1.7-2.3-fold of their original strength before being stabilized.

Different attempts have been performed in the past to improve plastic soils by waste material, and a few of them were utilized waste brick as a stabilizer material. Some of them were focused on the strength behavior of the soil stabilized with WBP but with little consideration given to the index and swelling behavior. The main purpose of this investigational study is to determine the optimum ratio of WBP at which the stabilization of MH soil is attained, and this could be used as subgrade material.

\section{Materials and methods}

The experimental work was directed primarily toward a study of the influence of waste brick powder on stabilize of some geotechnical properties of natural soils. Different laboratory tests were performed to study the influence of waste brick powder on the behavior of high-plasticity silt $(\mathrm{MH})$. The ratios of the waste brick powder used in the 
investigational study were $0 \%, 6 \%, 12 \%, 18 \%, 24 \%$, and $30 \%$ by dry weight of the mixture.

\subsection{Natural soil}

The natural soil used in this experimental work was brought from the Khalifan-Balisan road in Soran City in the Kurdistan Region of Iraq at depth $1.2 \mathrm{~m}$ in the second layer of the under the ground as shown in Fig. 1. In addition, the soil particles were very fine and sticky. Figure 2 shows the site of the field of study. The particle size distribution (PSD) curves, Atterberg limits, compaction characteristics, free swelling (FS), specific gravity, UCS, CBR, and permeability tests were performed according to ASTM standards for the natural soil samples. Furthermore, the samples of natural soil were mixed with different ratios of WBP $(6 \%, 12 \%, 18 \%$, $24 \%$, and $30 \%$ by dry weight of the soil sample). Figure 3 shows PSD curves for the natural soil sample and WBP content; according to PSD curves, about $78 \%$ and $96 \%$ of the natural soil and WBP, respectively, are finer than $0.075 \mathrm{~mm}$. In addition, about $41 \%$ of the soil is silt, and $62 \%$ of the brick powder is in clay particle size. Therefore, based on the unified soil classification system (USCS), the natural soil was classified as MH. The microstructural evaluation of the

Fig. 1 Natural soil used in the experiment after being washed
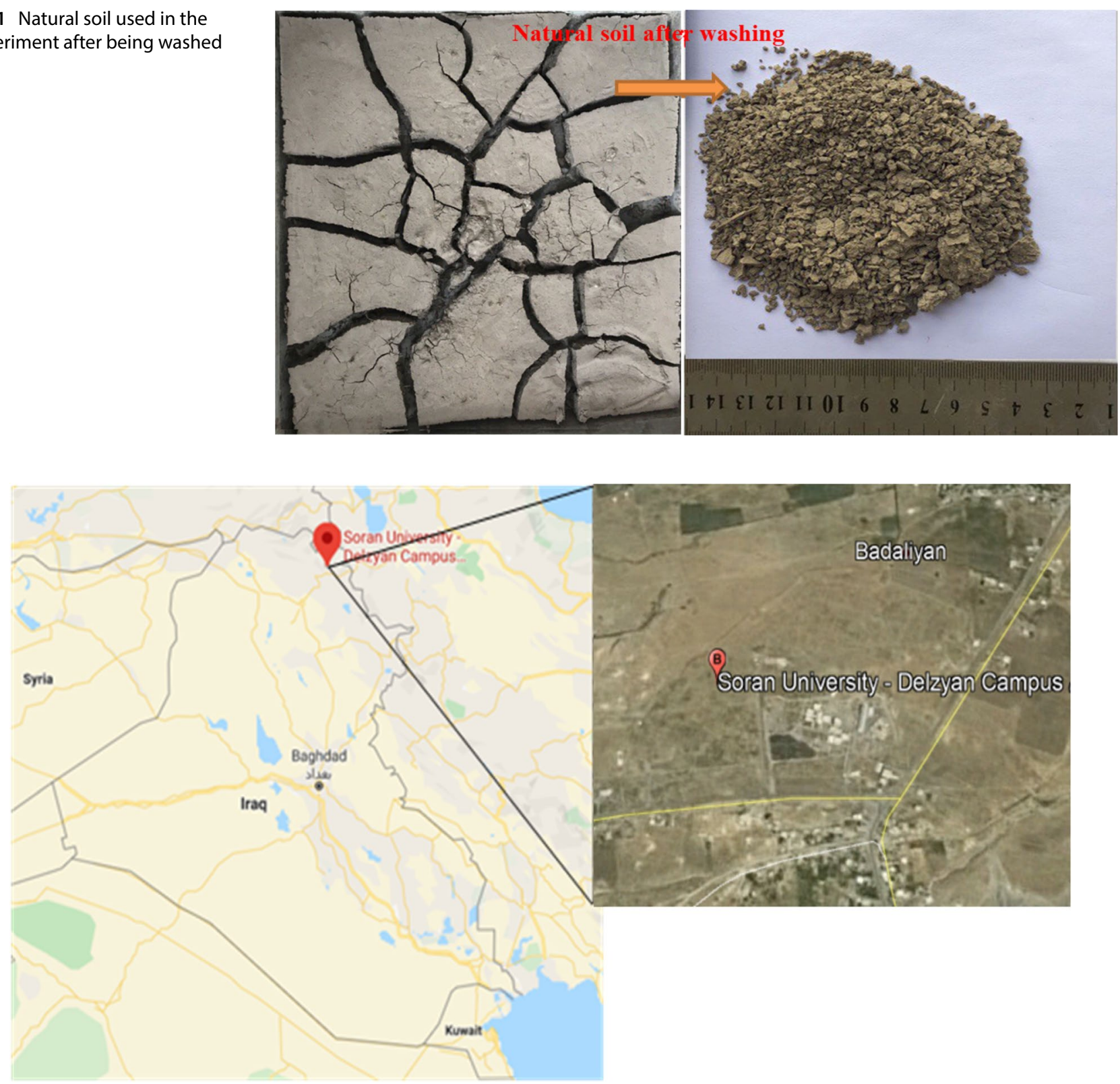

Fig. 2 Geographical location of (Soran University-Delzyan Campus-Soran City-Kurdistan of Iraq) 


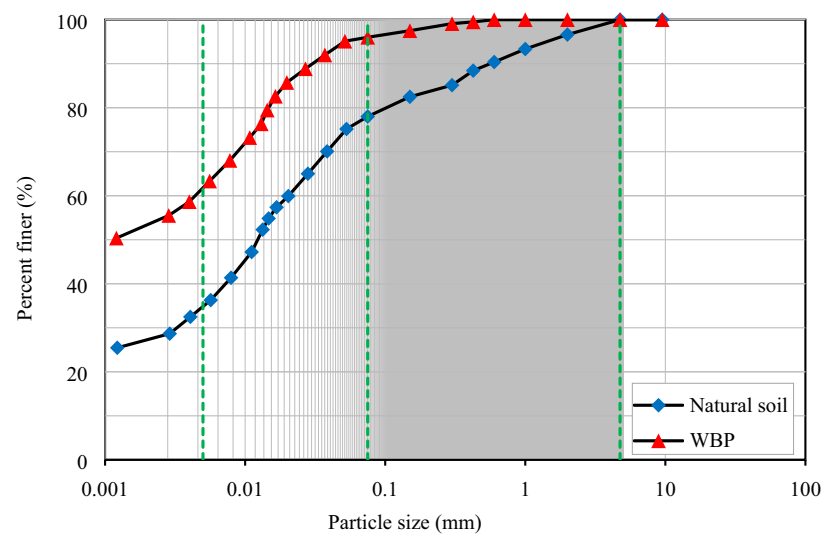

Fig. 3 PSD curves for the natural soil and WBP

natural soil is addressed by Fig. 4 and WBP using scanning electron microscopy (SEM). Also, the results of the tested natural soil are summarized in Table 1.

\subsection{Brick powder}

The waste brick powder used in the experimental study was obtained from waste fire clay brick through a crusher located at the Soran City north of Iraq, as shown in Fig. 5. It is red/yellow in color, fine in nature. The specific gravity of WBP was 2.76. In comparison with the natural soil, the precise gravity of the mixtures was increased when the WBP was combined with natural soil. The chemical compositions of WBP were defined by X-ray fluorescence (XRF), as shown in Table 2 . The test was conducted at a laboratory of Soran University. WBP is mostly composed of silica that

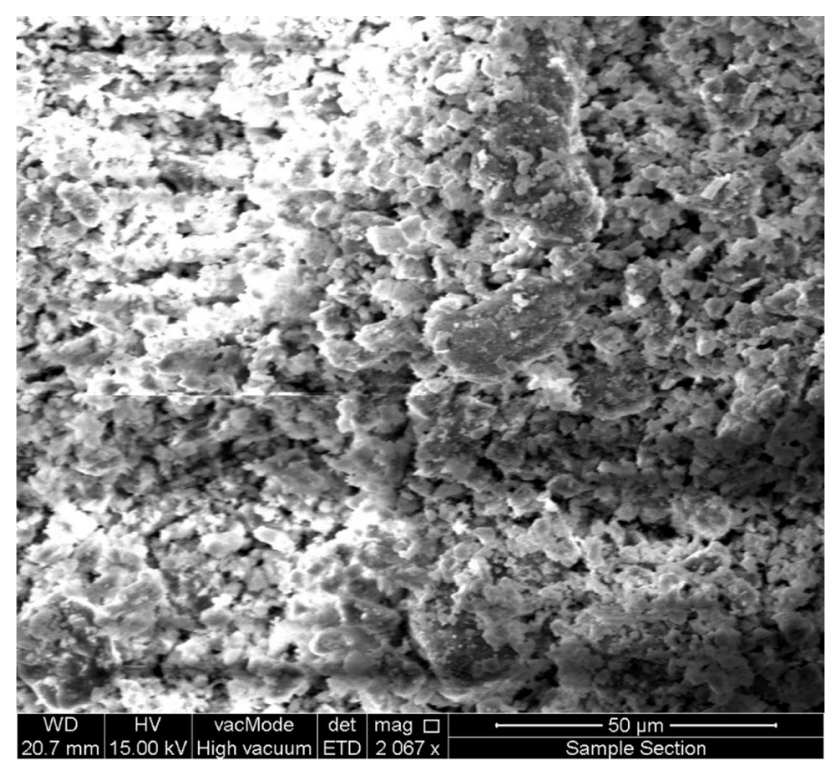

Fig. 4 The morphology of the natural soil using SEM
Table 1 Geotechnical properties of natural soil

\begin{tabular}{lll}
\hline Property & Value & Standard methods \\
\hline Liquid limit (\%) & 52.60 & ASTM_D4318 [24] \\
Plastic limit (\%) & 33.42 & ASTM_D4318 [24] \\
Plasticity index (\%) & 19.18 & ASTM_D4318 [24] \\
Linear shrinkage (\%) & 11.32 & BS_1377-2 [25] \\
Specific gravity & 2.67 & ASTM_D854 [26] \\
Soil type (USCS) & MH & ASTM_D2487 [27] \\
Free swelling (\%) & 7.85 & ASTM_D4546 [28] \\
OMC (\%) & 20.42 & ASTM_D698 [29] \\
MDD (g/cm $\left.{ }^{3}\right)$ & 1.74 & ASTM_D698 [29] \\
UCS (kN/m $\left.{ }^{2}\right)$ & 150 & ASTM_D2166 [30] \\
CBR & 3.20 & ASTM_D1883 [31] \\
Gravel (\%) & 0 & ASTM_D6913 [32] \\
Sand (\%) & 22 & ASTM_D6913 [32] \\
Silt (\%) & 44 & ASTM_D6913 [32] \\
Clay (\%) & 34 & ASTM_D6913 [32] \\
Coefficient of permeability & $3.050 \times 10^{-6}$ & ASTM_D5084 [33] \\
(cm/s) & & \\
\hline
\end{tabular}

constitutes $56.20 \%$ of WBP. The microstructural analysis of WBP using SEM is presented in Fig. 6.

\section{Analysis of test results}

In this part, results of these laboratory work, which have been performed on various high-plasticity silt and waste brick powder mixtures using a series of testing machines, are analyzed and discussed with the readily available papers in the literature.

\subsection{Atterberg limits test}

The Atterberg limits are the key parameters for measuring the critical water contents of fine-grained soil. Plasticity characteristics and their deformation of natural and stabilized soil are presented with index properties such as liquid limit (LL), plastic limit (PL), plasticity index (PI), and linear shrinkage (LS), as shown in Fig. 7. The WBP was mixed at different ratios ranging from $6 \%$ to $30 \%$, and a fair decline in the index properties is quite clear at different ratios of WBP content. It can be seen that $L L, P L, P I$, and $L S$ have declined with the increase in the WBP ratio up to a limit of $30 \%$. In addition to the ability to absorb water from WBP particles, WBP acts as an inner material since it is less than silty soil particles. Additionally, it can be found in Table 2 that WBP is of high content of silica $\left(\mathrm{SiO}_{2}\right.$ $=56.20 \%)$ yet of low content of lime $(\mathrm{CaO}=3.37 \%)$. As a consequence, a part of the silty soil is covered by the nonplastic product. Therefore, LL and PL were declined from

SN Applied Sciences 
Fig. 5 WBP used for this study after crushing

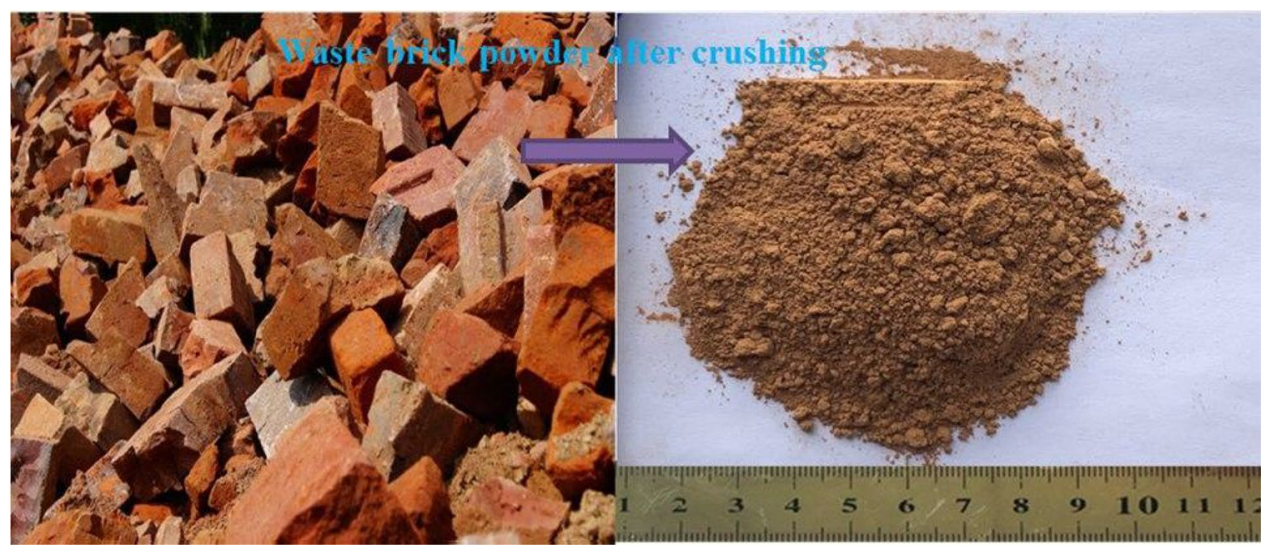

Table 2 Chemical composition of WBP

\begin{tabular}{lc}
\hline Compound & Percentages (\%) \\
\hline $\mathrm{SiO}_{2}$ & 56.20 \\
$\mathrm{Al}_{2} \mathrm{O}_{3}$ & 10.40 \\
$\mathrm{~K}_{2} \mathrm{O}$ & 1.88 \\
$\mathrm{Na}_{2} \mathrm{O}$ & 0.95 \\
$\mathrm{CaO}$ & 3.37 \\
$\mathrm{FeO}$ & 10.30 \\
$\mathrm{Fe}_{2} \mathrm{O}_{3}$ & 7.54 \\
$\mathrm{MgO} \mathrm{O}$ & 2.65 \\
$\mathrm{TiO}_{2}$ & 0.96 \\
Other composition & 5.40 \\
\hline
\end{tabular}

52.60 to $32.26 \%$, and from 33.42 to $19.6 \%$, respectively [ 14 , 34]. The PI and LS were significantly declined from 19.18 to $12.62 \%$ and from 11.32 to $4.13 \%$, respectively, when the WBP ratio was raised to $30 \%$ by the dry weight of the sample soil [35]. The following declinations of $38.7 \%$ for LL, $41.2 \%$ for $\mathrm{PL}, 34.2 \%$ for $\mathrm{PI}$, and $63.52 \%$ for $\mathrm{LS}$ are attained by the addition of $30 \%$ of WBP. Similar observations supporting these findings have been made by some other researchers [6, 36-39].

The position of natural and stabilized soil was described in the plasticity chart, as illustrated in Fig. 8. It could be noted that the increase in the WBP ratio converts natural soil from $\mathrm{MH}$ into $\mathrm{CL}$ as per the unified soil classification system [38].

\subsection{Compaction test}

Proper compaction of soils is essential for most of the earthwork projects, as it helps achieve some physical features required for the appropriate behavior of soils under various loadings. The height was divided into three
Fig. 6 The morphology of WBP using SEM

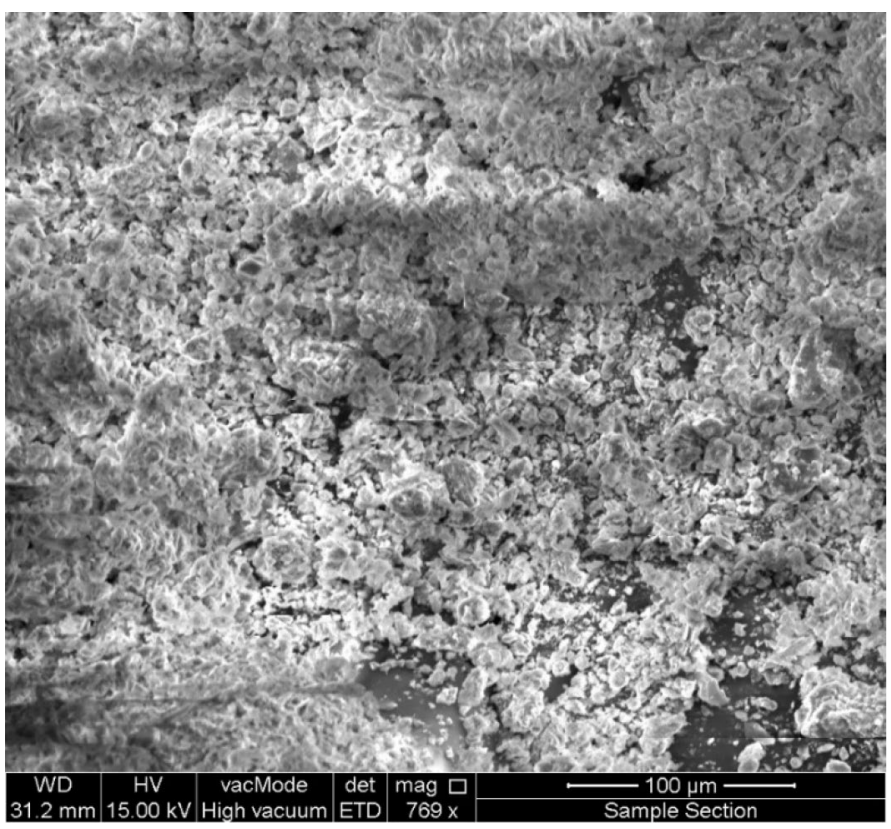

SN Applied Sciences A SPRINGER NATURE journal 


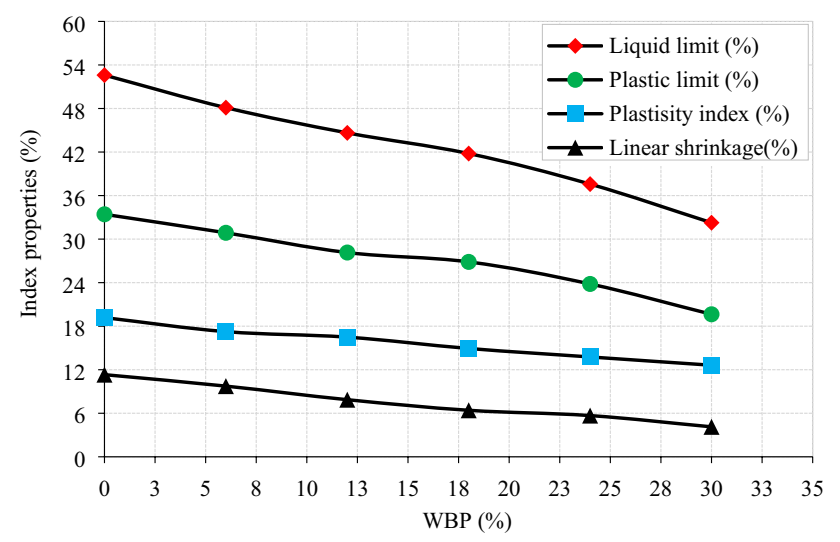

Fig. 7 Differences of features of the index versus different ratios of WBP

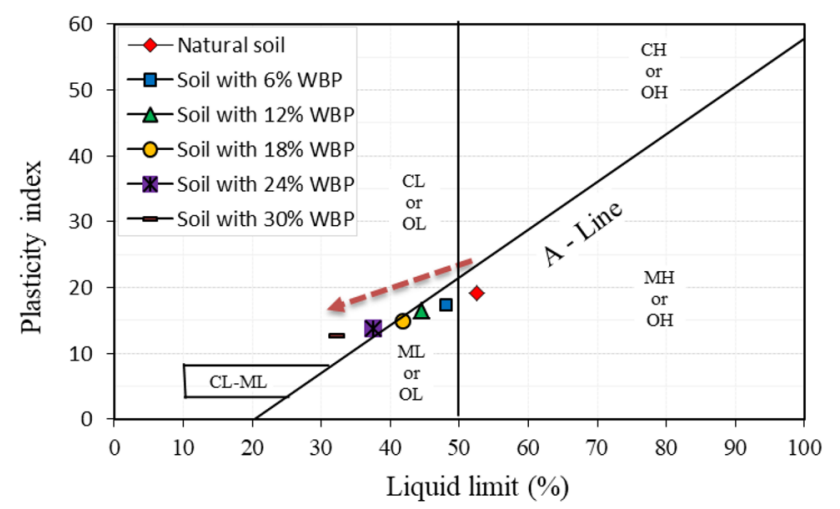

Fig. 8 Positions of natural soil with various WBP ratios on the plasticity chart

layers for the specimens. Special hammer and mold were used for compacting samples to find the MDD and OMC, as shown in Fig. 9. The standard compaction tests were performed for natural and stabilized soil with several ratios of WBP content. Furthermore, the MDD and OMC were found for natural and stabilized soil with different ratios $(6 \%, 12 \%, 18 \%, 24 \%$, and $30 \%)$ of WBP. Figure 10 implies that, as the moisture content continues to increase, the dry density of the normal and stable soil increases to the point at which the MDD and OMC are reached; subsequently, the dry density decreases for the specified situations. For natural and stabilized soil samples, the highest point for every curve reflects the MDD and OMC at that moment [3,22].

The MDD and OMC values for the natural soil were found to be $1.74 \mathrm{~g} / \mathrm{cm}^{3}$ and $20.42 \%$, respectively. The addition of WBP to the samples significantly increased the MDD from 1.74 to $1.83 \mathrm{~g} / \mathrm{cm}^{3}$ (Fig. 11a), while the addition of $30 \%$ of WBP was decreased the OMC from 20.42 to 13.84\% (Fig. 11b). According to the author's interpretation, an increase in the MDD values was mainly dependent on the addition of WBP that affects the overall behavior of the samples, and the WBP acted as non-water-absorbing nature and had higher specific gravity than silty soil particles. Moreover, this may be due to the reduction in the ratios of intergranular soil voids $[40,41]$. On the other hand, the reduction in $\mathrm{OMC}$ is due to the lower water absorption capacity of the WBP particles. Similar findings were found by using different types of non-plastic additions in various soils $[42,43]$.

\subsection{Specific gravity}

The samples were dried at $110^{\circ} \mathrm{C}$, and the specific gravity was determined by the pycnometer method according to ASTM standards. The findings of the examination showed that the specific gravity of silty soil was 2.67 at $20^{\circ} \mathrm{C}$ and the specific gravity of WBP was 2.76 at $20^{\circ} \mathrm{C}$. It was observed that the specific gravity of the mixture increased during the addition of WBP. This was because
Fig. 9 Apparatus, mold, and samples of UCS test

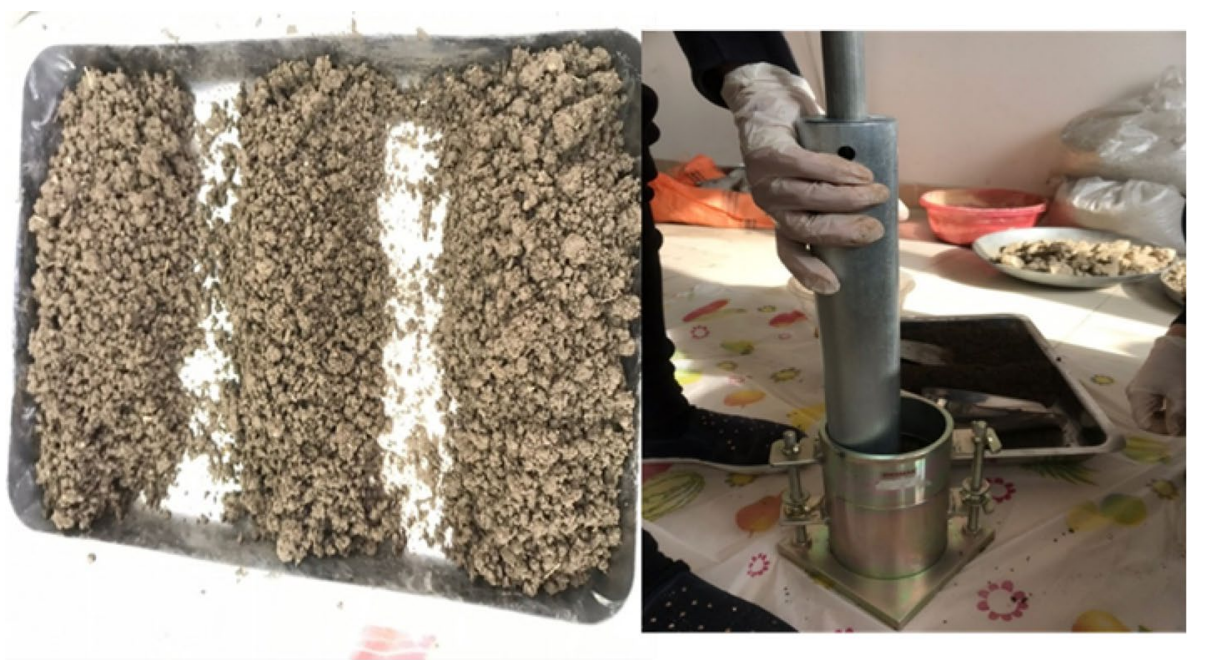




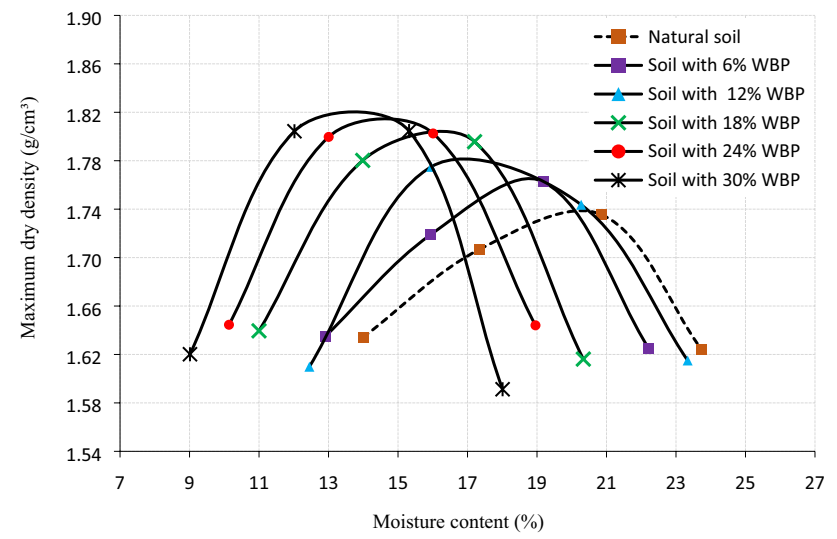

Fig. 10 Relationship between the content of dry density and moisture content for natural soil and WBP content

the stabilizer's specific gravity higher than the soil sample; consequently, the specific gravity of the mixture increased. In addition, it can be seen that by adding WBP to the silty soil up to $30 \%$, the specific gravity of the mixtures increases gradually from 2.67 to 2.73, as shown in Fig. 12 . This result agrees with Başer [44], Tak et al. [45] reported that by increasing a higher specific gravity to soil with lower specific gravity, the mixtures have higher specific gravity than natural soil.

\subsection{Free swelling test}

Free swelling is the swelling percentage of natural and stabilized soil with various ratios of WBP that is determined as per [46]. The samples that passed through No. 10 sieve $(2.00 \mathrm{~mm})$ were determined at OMC and MDD.

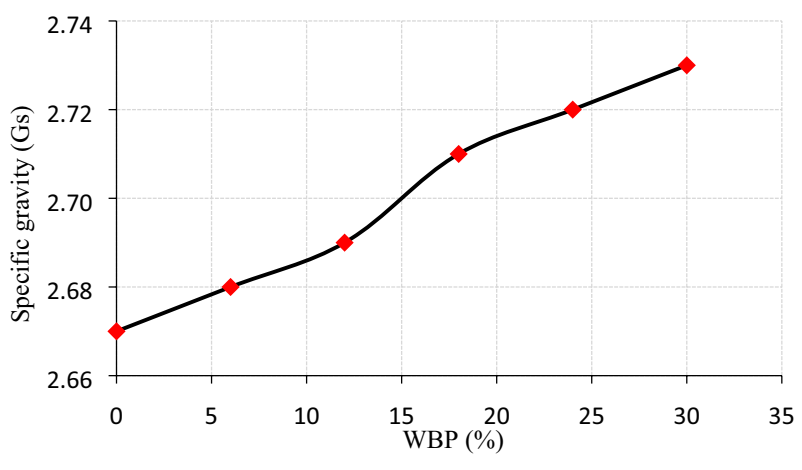

Fig. 12 Variation of specific gravity with a percentage of WBP content

Samples have been prepared with a diameter and height of $5 \mathrm{~cm}$ and $2 \mathrm{~cm}$, respectively. Mass and volume control gained the requisite density. The soil samples were placed into two layers according to item No. 9.1.1 [46] for a mass that is compacted to a prearranged volume for all layers. The soil sample was controlled horizontally and drowned in the approved vertical stress in the oedometer device; the vertical strain that occurs due to wetting is called the ratio of free swelling. In addition, the free swelling of the natural and stabilized soil was decreased from 7.85 to $2.54 \%$, when WBP is increased up to $30 \%$ (Fig. 13). The findings showed that the impact of WBP was affected by the silty soil has a good impact on soil swelling properties by decreasing its swelling nature $[47,48]$. This is due to the incorporation of non-plastic material that serves as an inert material to the silty soil

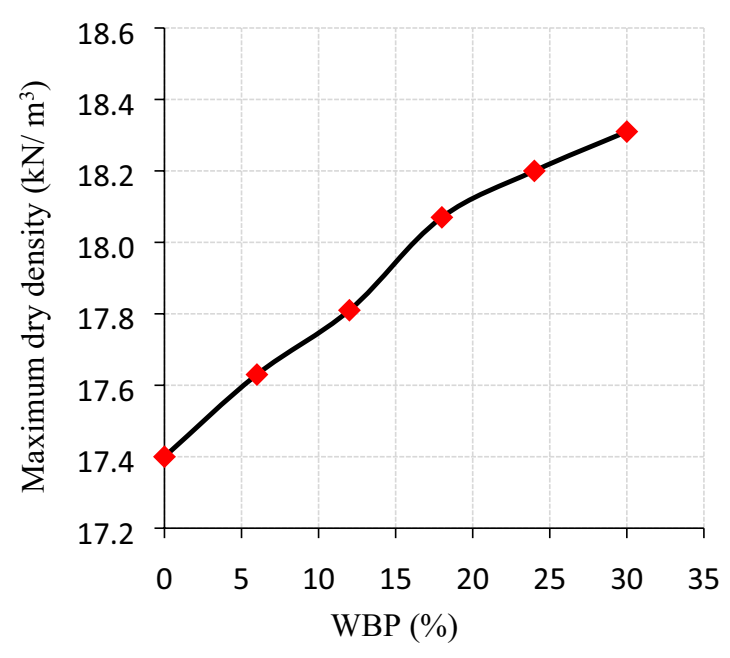

(a)

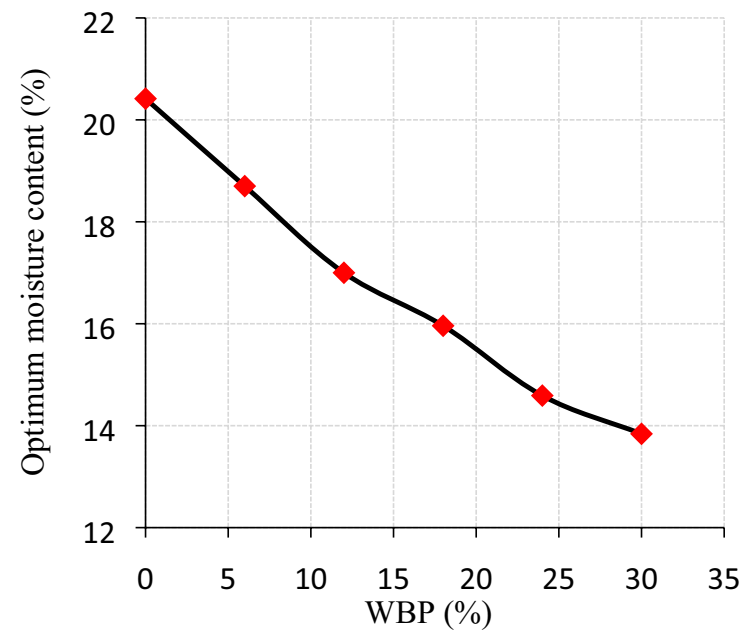

(b)

Fig. 11 (a) Variations between OMC and WBP, (b) MDD and WBP contents 


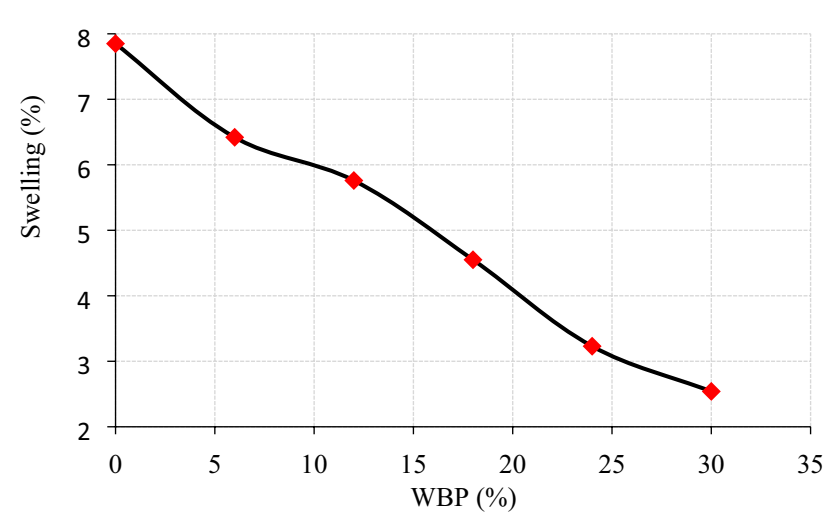

Fig. 13 Variation of free swelling with WBP content

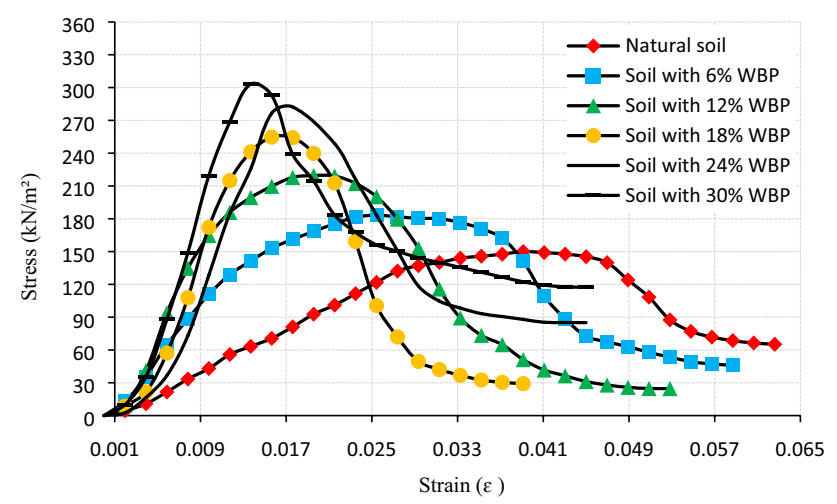

Fig. 14 Stress-strain curves of silty soil with various ratios of WBP

or because of the filling of the voids of silty soil by a finer and inert material like WBP grains [49-52].

\subsection{Unconfined compressive strength test}

The unconfined compressive strength (UCS) test is one of the most common methods of shear test for being fast and cheap of measuring the shear strength of soils tested under zero confining pressure. The UCS tests were carried out for natural and stabilized soil with several ratios $(6 \%$, $12 \%, 18 \%, 24 \%$, and $30 \%$ ) of WBP at their OMC and MDD. The height and width of the sample were recorded. Special piston and mold were factory-made for packing UCS samples to attain the UCS soil specimens. The loading speed was fixed at $0.5 \mathrm{~mm} / \mathrm{min}$. The relation of stress versus axial strain $(\varepsilon)$ for samples tested with various ratios of WBP is shown in Fig. 14. It can be seen that the increase in WBP increases the UCS values from 150 to $303.28 \mathrm{kN} / \mathrm{m}^{2}$ when the WBP ratio reaches to $30 \%$ (Fig. 15). In light of Lade et al. [53], Ni et al. [54], Zuo and Baudet [55], Cabalar et al. [56], with the increase in WBP to its final limit of $30 \%$, the voids of natural soil are gradually filled up. Based on the explanations given in Cabalar, Karabash [57], Gupta et al.

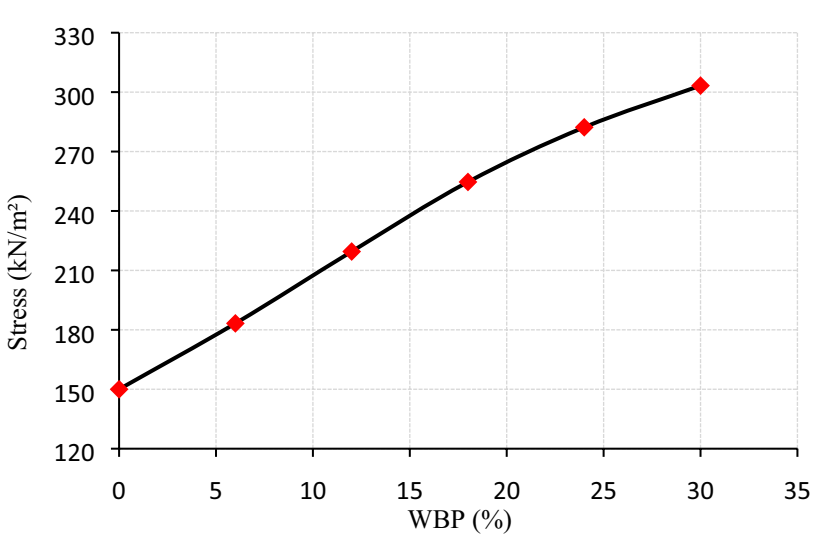

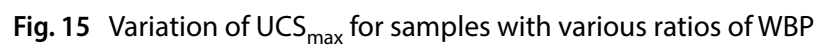

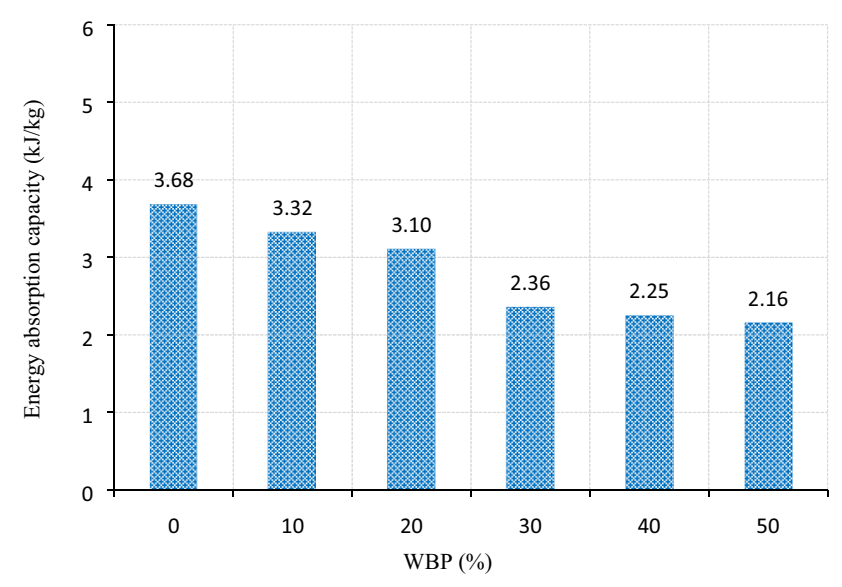

Fig. 16 Relation between energy absorption capacity and WBP

[22], and the observations made on the results, it can be concluded that the overall behavior of the samples was governed by the void ratio associated with the WBP particles of the tested samples. Moreover, it was dominated by the 'bonds' (cementation) that has taken place between the natural soil and WBP particles.

Figure 16 illustrates the energy absorption capacity, which gradually decreased by about $41.3 \%$ at $30 \%$ of WBP addition into the sample. It can be seen that the ductility of the samples tested decreased by the addition of WBP. This indicates that a transition from ductile to brittle fracture resulted from the samples were prepared and tested immediately without curing.

\subsection{California bearing ratio test}

California bearing ratio (CBR) test was conducted on samples at OMC and MDD with different ratios of WBP content. The samples' CBR values were estimated to be $3.20 \%$, $6.85 \%, 9.50 \%, 13.00 \%, 15.60 \%$, and $17.30 \%$, for the natural 


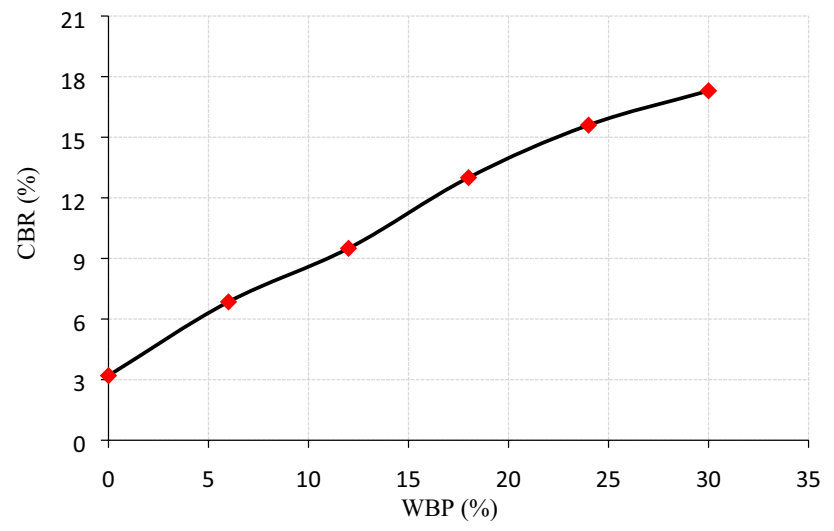

Fig. 17 Variation of $\mathrm{CBR}_{\max }$ for the samples with various ratios of WBP

and stabilized soil (Fig. 17). With the addition of WBP up to $30 \%$, the CBR value of the samples was increased. For example, the CBR value, which was $3.20 \%$ for the natural soil, was increased by up to $17.30 \%$ when $30 \%$ of WBP added to the soil sample. The change in CBR value by the addition of WBP up to $30 \%$ is attributed to the great contribution of WBP on the CBR performance of the samples. Furthermore, the bearing capacity of the whole samples increased as the voids between soil grains are filled up by $30 \%$ of WBP $[55,58,59]$. Additionally, the increment of MDD with the addition percentages of WBP increases both the UCS and CBR values of the soil samples. Moreover, these features suggest that a higher frictional resistance of the samples with $30 \%$ of WBP causes a higher CBR value $[3,43]$.

The CBR test is commonly used to measure the subgrade strength of roads and pavements, to distinguish elastic pavement subgrade components, and to establish layers of pavement thickness. Figure 18 gives the information used for capping and subbase thickness configuration in the present study. It is easily shown that a subbase thickness with a CBR value of more than $15 \%$ will be $150 \mathrm{~mm}$ from Table 3. In addition, where the subgrade CBR result is between 2.5 and $15 \%$, the subbase can be built either with a subbase thickness of $150 \mathrm{~mm}$ with different capping thicknesses or with a subbase alone. [60]. The higher the $C B R$ values, the thinner the subbase and capping. Therefore, the rise in $C B R$ values due to the inclusion of WBP results in a reduction from 300 to $150 \mathrm{~mm}$ in the thickness of the subbase surface (Fig. 19). Ene and Okagbue [61], Okagbue and Onyeobi [62], Cabalar et al. [63], and Gupta et al. [22] have similar outcomes that confirm the obtained results in the current analysis by the authors.

Figure 20 shows the relationship between the resilient modulus (MR) and CBR for various percentages of WBP. The resilient modulus could be calculated based on CBR

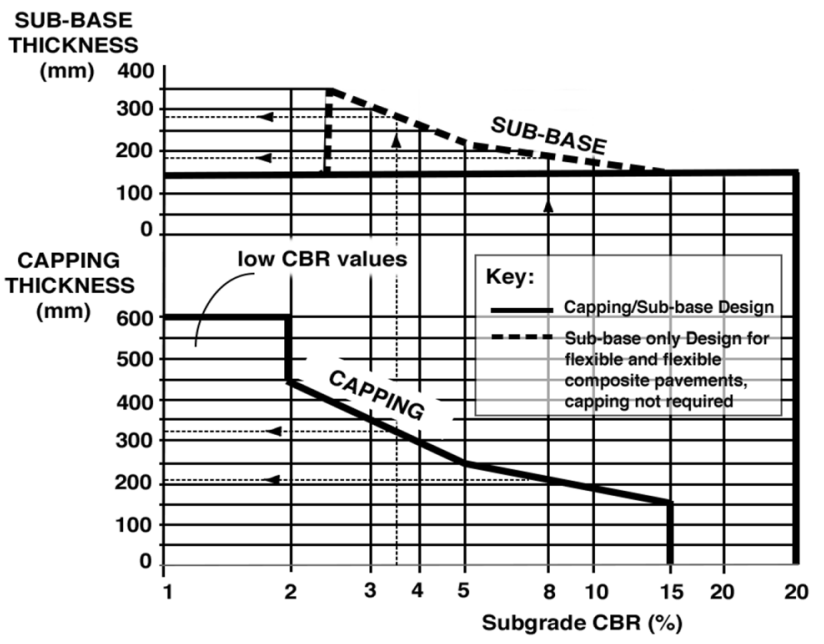

Fig. 18 Capping and subbase thickness design [60]

values from a linear equation that was proposed by Garber and Hoel [64], as shown in Fig. 20. With the addition of the WBP, the CBR values increased; consequently, the resilient modulus increased. This occurred because, with the addition of WBP, the MDD values of the soil samples were increased.

\subsection{Permeability test}

The permeability tests were carried out for natural and stabilized soil with different ratios of WBP $(6 \%, 12 \%, 18 \%$, $24 \%$, and $30 \%$ ) at OMC and MDD, as shown in Fig. 21. It can be seen that there is a clear trend of decrement in the coefficient of permeability $(K)$ of the mixtures from (3.05 E-06 to $1.20 \mathrm{E}-06) \mathrm{cm} / \mathrm{s}$ when WBP is increased up to $30 \%$. It is likely since WBP decreases the void ratio, consequently, decreases the hydraulic conductivity values. Furthermore, the decrease in the hydraulic conductivity correlates well with the increase in MDD values that is relevant to the addition of WBP, which is very important in the design of the earth dam core. Phani Kumar, Sharma [42], and Kalkan [38] reported similar results using waste materials in soil matrices.

\section{Conclusions}

This study conducted the use of WBP in some geotechnical engineering applications to reduce the amount of waste material and decreasing environmental issues from disposal to landfills. An intensive series of testing, including Atterberg limits, compaction, specific gravity, free swelling, unconfined compressive strength (UCS), California bearing ratio $(C B R)$, and permeability tests, have performed for the natural soil sample and stabilized with different WBP ratios 
Table 3 Summary of pavement design layers

\begin{tabular}{|c|c|c|c|c|}
\hline \multirow[t]{3}{*}{ Samples } & \multirow[t]{3}{*}{ CBR (\%) } & \multicolumn{3}{|c|}{ Pavement design alternatives } \\
\hline & & $(1)$ & $(2)$ & \\
\hline & & Subbase (mm) & Capping $(\mathrm{mm})$ & Subbase $(\mathrm{mm})$ \\
\hline Natural soil & 3.20 & 150 & 320 & 300 \\
\hline Soil with $6 \%$ WBP & 6.85 & 150 & 220 & 200 \\
\hline Soil with $12 \%$ WBP & 9.50 & 150 & 190 & 170 \\
\hline Soil with $18 \%$ WBP & 13.00 & 150 & 170 & 160 \\
\hline Soil with $24 \%$ WBP & 15.60 & 150 & 150 & 150 \\
\hline Soil with $30 \%$ WBP & 17.30 & 150 & 150 & 150 \\
\hline
\end{tabular}

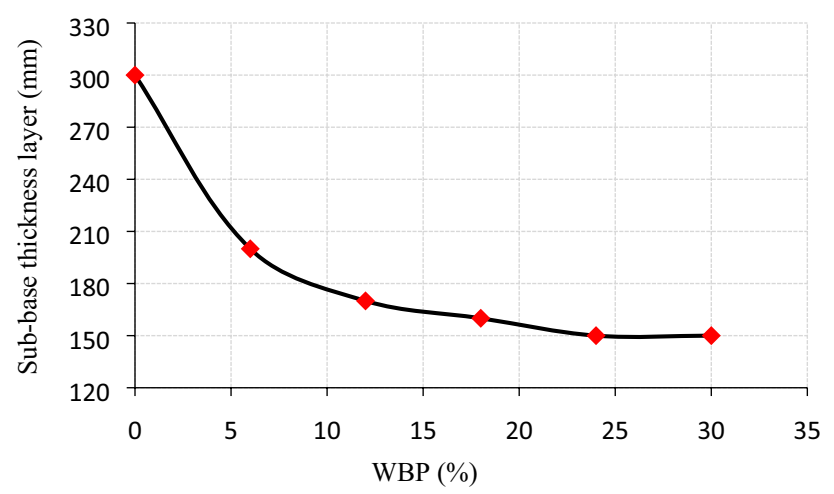

Fig. 19 Variation of pavement thickness design with various ratios of WBP content

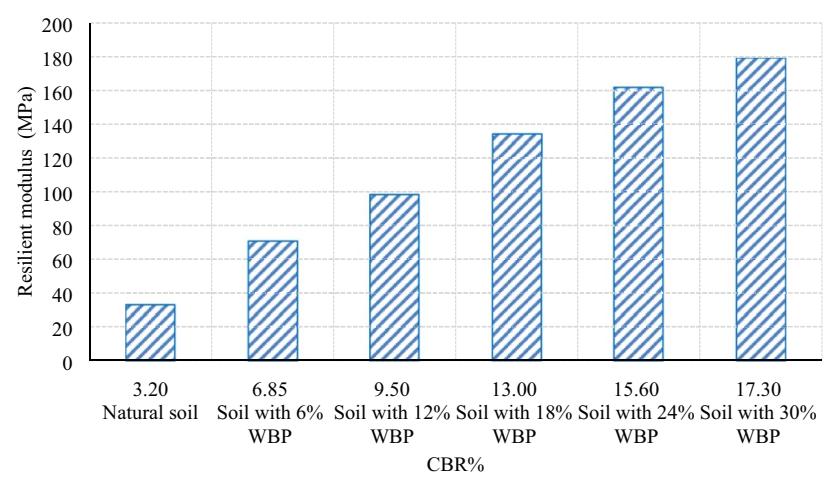

Fig. 20 The relation between resilient modulus and CBR values

$(6 \%, 12 \%, 18 \%, 24 \%$, and $30 \%$ by dry weight of the soil sample). The findings of this study were listed as follows:

1. Liquid limit, plastic limit, plasticity index, and linear shrinkage of natural and stabilized soils were decreased as follows $(38.7 \%, 41.2 \%, 34.2 \%$, and $63.52 \%)$ with the increment of WBP ratio to its highest ratio of $30 \%$.

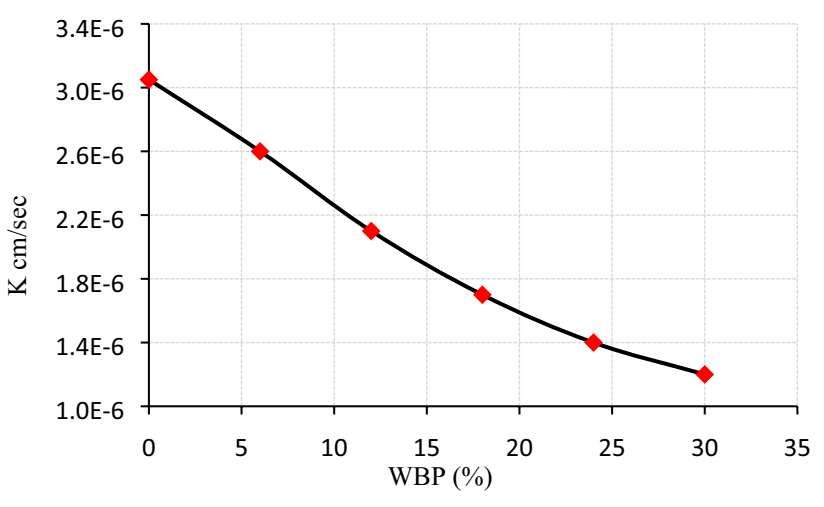

Fig. 21 The variation between $k$ and WBP content

2. The increment of the WBP ratio up to $30 \%$ improved the soil and shifted it from the MH group to be within the $\mathrm{CL}$ group.

3. The increment of WBP into the samples progressively caused a decrease in OMC and an increase in MDD by $32.22 \%$ and $5.23 \%$, respectively, when the WBP ratio was increased to its highest limit of $30 \%$.

4. The specific gravity of natural and stabilized soil went up by $3.37 \%$, whereas the free swelling of the same case went down by $67.6 \%$ when the WBP ratio was increased to its highest limit of $30 \%$.

5. The UCS of the natural and stabilized soil continued increasing up to $102.2 \%$, with an addition of $30 \%$ of the WBP.

6. The increment of WBP to $30 \%$ has increased the CBR by $440.6 \%$ in relation to that of the natural soil.

7. The subbase thickness layer of the roadway kept on decreasing until the increment of WBP achieves a fall of $50 \%$ to its highest limit of $30 \%$.

8. The CBR values increased by the addition of WBP; as a result of that, the thickness of the subbase was decreased. The effect of adding WBP is almost negligible when the incremental ratio exceeds $18 \%$ of WBP. Therefore, it could be considered that the ratio of $18 \%$ 
of WBP is a critical ratio for the improvement of highplasticity silt at the subgrade layer.

9. The coefficient of permeability was decreased by $60.6 \%$, for a WBP percentage rise of up to $30 \%$.

\section{Compliance with ethical standards}

Conflict of interest The authors declare that they have no conflict of interest.

\section{References}

1. Srikanth Reddy S, Prasad ACSV, Vamsi Krishna N (2018) Limestabilized black cotton soil and brick powder mixture as subbase material. Adv Civ Eng 2018:5834685. https://doi. org/10.1155/2018/5834685

2. Hairulla Betaubun $P(2016)$ The effect of using brick waste to the stabilization of soft soil due to the unconfined compression. J Basic Appl Sci Res 6(2):1-8

3. Kinuthia JM, Nidzam RM (2011) Towards zero industrial waste: utilisation of brick dust waste in sustainable construction. Waste Manag 31(8):1867-1878. https://doi.org/10.1016/j.wasma n.2011.03.020

4. James J, Pandian PK (2018) Strength and microstructure of micro ceramic dust admixed lime stabilized soil. Revista de la Construcción Journal of Construction 17(1):5-22

5. Hidalgo C, Carvajal G, Muñoz F (2019) Laboratory evaluation of finely milled brick debris as a soil stabilizer. Sustainability 11(4):967

6. Raut SP, Ralegaonkar RV, Mandavgane SA (2011) Development of sustainable construction material using industrial and agricultural solid waste: a review of waste-create bricks. Constr Build Mater 25(10):4037-4042. https://doi.org/10.1016/j.conbuildma t.2011.04.038

7. Saand A, Zardari MA, Keerio MA, Shaikh SH, Bangwar DK (2020) Suitability of brick kiln waste as a stabilizer for clayey soils. Sci Iran 27:2258-2263

8. Salman MM, Yousif MZ (2019) The effect of waste brick powder as cement weight replacement on properties of sustainable concrete. J Eng Sustain Dev 22(02 Part-6):116-130

9. Al-Baidhani A, Al-Taie A (2019) Review of brick waste in expansive soil stabilization and other civil engineering applications. J Geotech Stud 4(3):14-23. https://doi.org/10.5281/zenodo.34592 35

10. Dang LC, Fatahi B, Khabbaz H (2016) Behaviour of expansive soils stabilized with hydrated lime and bagasse fibres. Proc Eng 143:658-665. https://doi.org/10.1016/j.proeng.2016.06.093

11. Sabat AK, Pati S (2014) A review of literature on stabilization of expansive soil using solid wastes. Electron J Geotech Eng 19:6251-6267

12. Taha R, Al-Rawas A, Al-Jabri K, Al-Harthy A, Hassan H, Al-Oraimi $S$ (2004) An overview of waste materials recycling in the Sultanate of Oman. Resour Conserv Recycl 41(4):293-306. https://doi. org/10.1016/j.resconrec.2003.10.005

13. Wani KS, Mir BJG, Engineering G (2020) Stabilization of weak dredged soils by employing waste boulder crusher dust: a laboratory study. Geotech Geol Eng 38:1-16

14. Fauzi A, Rahman WMNWA, Jauhari Z (2013) Utilization waste material as stabilizer on kuantan clayey soil stabilization. Proc Eng 53:42-47. https://doi.org/10.1016/j.proeng.2013.02.007
15. Blayi RA, Sherwani AFH, Ibrahim HH, Faraj RH, Daraei A (2020) Strength improvement of expansive soil by utilizing waste glass powder. Case Stud Construct Mater 13:e00427. https:// doi.org/10.1016/j.cscm.2020.e00427

16. Chen M-z, Lin J-t, Wu S-p, Liu C-h (2011) Utilization of recycled brick powder as alternative filler in asphalt mixture. Constr Build Mater 25(4):1532-1536. https://doi.org/10.1016/j.conbu ildmat.2010.08.005

17. Wu S, Zhu J, Zhong J, Wang D (2011) Experimental investigation on related properties of asphalt mastic containing recycled red brick powder. Constr Build Mater 25(6):2883-2887. https://doi.org/10.1016/j.conbuildmat.2010.12.040

18. Arulrajah A, Piratheepan J, Aatheesan T, Bo MW (2011) Geotechnical properties of recycled crushed brick in pavement applications. J Mater Civ Eng 23(10):1444-1452

19. Arulrajah A, Piratheepan J, Disfani MM, Bo MW (2013) Geotechnical and geoenvironmental properties of recycled construction and demolition materials in pavement subbase applications. J Mater Civ Eng 25(8):1077-1088

20. Arulrajah A, Disfani MM, Horpibulsuk S, Suksiripattanapong C, Prongmanee N (2014) Physical properties and shear strength responses of recycled construction and demolition materials in unbound pavement base/subbase applications. Constr Build Mater 58:245-257. https://doi.org/10.1016/j.conbuildma t.2014.02.025

21. Poon CS, Chan D (2006) Feasible use of recycled concrete aggregates and crushed clay brick as unbound road sub-base. Constr Build Mater 20(8):578-585. https://doi.org/10.1016/j. conbuildmat.2005.01.045

22. Gupta G, Sood H, Gupta PK (2018) Brick kiln dust waste management through soil stabilization. In: International conference on sustainable waste management through design. Springer, pp 422-431

23. Gupta G, Sood H, Gupta P (2020) Performance evaluation of pavement geomaterials stabilized with pond ash and brick kiln dust using advanced cyclic triaxial testing. Materials 13(3):553

24. ASTM_D4318 (2017) Standard test methods for liquid limit, plastic limit, and plasticity index of soils. ASTM International, West Conshohocken, PA

25. ASTM_D854 (1990) Methods of test for soils for civil engineering purposes. Part 2: classification test. British Standards Institution, London

26. ASTM_D854 (2014) Standard test methods for specific gravity of soil solids by water pycnometer. ASTM International, West Conshohocken, PA

27. ASTM_D2487 (2017) Standard practice for classification of soils for engineering purposes (unified soil classification system). ASTM International, West Conshohocken, PA

28. ASTM_D4546 (2014) Standard test methods for one-dimensional swell or collapse of soils. ASTM International, West Conshohocken, PA

29. ASTM_D698 (2014) Standard test methods for laboratory compaction characteristics of soil using standard effort. ASTM International, West Conshohocken, PA

30. ASTM_D2166 (2016) Standard test method for unconfined compressive strength of cohesive soil. ASTM International, West Conshohocken, PA

31. ASTM_D1883 (2016) Standard test method for California bearing ratio (CBR) of laboratory-compacted soils. ASTM International, West Conshohocken, PA

32. ASTM D6913 (2017) Standard test methods for particle-size distribution (gradation) of soils using sieve analysis. ASTM International, West Conshohocken, PA

33. ASTM_D5084 (2016) Standard test methods for measurement of hydraulic conductivity of saturated porous materials using a 
flexible wall permeameter. ASTM International, West Conshohocken, PA

34. Nuruzzaman M, Hossain MA (2014) Effect of soda lime glass dust on the properties of clayey soil. Glob J Res Eng

35. Kalkan E, Akbulut S (2004) The positive effects of silica fume on the permeability, swelling pressure and compressive strength of natural clay liners. Eng Geol 73(1-2):145-156

36. Kalkan E (2011) Impact of wetting-drying cycles on swelling behavior of clayey soils modified by silica fume. Appl Clay Sci 52(4):345-352

37. Igwe O, Adepehin EJ (2017) Alternative approach to clay stabilization using granite and dolerite dusts. Geotech Geol Eng 35(4):1657-1664

38. Kalkan E (2006) Utilization of red mud as a stabilization material for the preparation of clay liners. Eng Geol 87(3-4):220-229

39. Ibrahim HH, Alshkane YM, Mawlood YI, Noori KMG, Hasan AM (2020) Improving the geotechnical properties of high expansive clay using limestone powder. Innov Infrastruct Solut 5(3):112. https://doi.org/10.1007/s41062-020-00366-z

40. Rahman MM, Lo S (2008) The prediction of equivalent granular steady state line of loose sand with fines. Geomech Geoeng Int J 3(3):179-190

41. Cabalar AF (2010) Applications of the oedometer, triaxial and resonant column tests to the study of micaceous sands. Eng Geol 112(1-4):21-28

42. Phani Kumar B, Sharma RS (2004) Effect of fly ash on engineering properties of expansive soils. J Geotech Geoenviron Eng 130(7):764-767

43. Cabalar AF, Mustafa WS (2017) Behaviour of sand-clay mixtures for road pavement subgrade. Int J Pavement Eng 18(8):714-726

44. Başer $O$ (2009) Stabilization of expansive soils using waste marble dust

45. Tak D, Sharma JK, Grover K (2018) Use of Kota stone powder to improve engineering properties of black cotton soil. In: Paper presented at the Indian geotechnical conference IGC 2018, Bengaluru, pp 13-15

46. ASTM (2014) Standard test methods for one-dimensional swell or collapse of soils. ASTM D4546

47. Mohanty S, Pradhan P, Mohanty C (2016) Consolidation and drainage characteristics of expansive soil stabilized with fly ash and dolochar. Geotech Geol Eng 34(5):1435-1451

48. Phanikumar B, Sharma RS (2007) Volume change behavior of fly ash-stabilized clays. J Mater Civ Eng 19(1):67-74

49. Pastor JL, Tomás R, Cano M, Riquelme A, Gutiérrez E (2019) Evaluation of the improvement effect of limestone powder waste in the stabilization of swelling clayey soil. Sustainability 11(3):679

50. Bhavsar SN, Joshi HB, Patel AJ (2014) Effect of burnt brick dust on engineering properties on expansive soil
51. Saand A, Zardari MA, Keerio MA, Shaikh SH, Bangwar DK (2018) Suitability of brick kiln waste as a stabilizer to clayey soils. Sci Iran 27:2258-2263

52. Ogila WAM (2016) The impact of natural ornamental limestone dust on swelling characteristics of high expansive soils. Environ Earth Sci 75(24):1493

53. Lade PV, Liggio C, Yamamuro JA (1998) Effects of non-plastic fines on minimum and maximum void ratios of sand. Geotech Test J 21:336-347

54. Ni Q, Tan T, Dasari G, Hight D (2004) Contribution of fines to the compressive strength of mixed soils. Géotechnique 54(9):561-569

55. Zuo L, Baudet BA (2015) Determination of the transitional fines content of sand-non plastic fines mixtures. Soils Found 55(1):213-219

56. Cabalar A, Demir S, Khalaf M (2019) Liquefaction resistance of different size/shape sand-clay mixtures using a pair of bender element-mounted molds. J Test Eval. https://doi.org/10.1520/ JTE20180677

57. Cabalar AF, Karabash Z (2019) Influence of cement type and sample preparation on the small-strain behaviour of sands. Arab J Sci Eng 44(10):8835-8848

58. Carrera A, Coop M, Lancellotta R (2011) Influence of grading on the mechanical behaviour of Stava tailings. Géotechnique 61(11):935-946

59. Ke L, Takahashi A (2012) Strength reduction of cohesionless soil due to internal erosion induced by one-dimensional upward seepage flow. Soils Found 52(4):698-711

60. HD_26/06 (2006) Pavement design and maintenance: design manual for roads and bridges (DMRB), vol 7. The Stationery Office London

61. Ene E, Okagbue C (2009) Some basic geotechnical properties of expansive soil modified using pyroclastic dust. Eng Geol 107(1-2):61-65

62. Okagbue C, Onyeobi T (1999) Potential of marble dust to stabilise red tropical soils for road construction. Eng Geol 53(3-4):371-380

63. Cabalar A, Hassan D, Abdulnafaa M (2017) Use of waste ceramic tiles for road pavement subgrade. Road Mater Pavement Design 18(4):882-896

64. Garber NJ, Hoel LA (2014) Traffic and highway engineering. Cengage Learning, Boston

Publisher's Note Springer Nature remains neutral with regard to jurisdictional claims in published maps and institutional affiliations. 